\title{
Responsabilidade do Cirurgião-dentista com o prontuário clínico
}

\author{
Responsibility of the Surgeon-dentist with the clinical
}

Responsabilidad del Cirujano-dentista con el prontuario clínico

\begin{abstract}
Fernanda Braga Peixoto ${ }^{1 *}$, Renata Rodrigues Feitoza², Cibelle Teresa de Albuquerque Machado², Jessyka Dantas Ramos Nascimento².
\end{abstract}

\section{RESUMO}

Objetivo: O presente trabalho teve como objetivos fornecer conhecimento, por meio de uma revisão de literatura a responsabilidade do Cirurgião-dentista conhecer a legislação pertinente conduta que pode substanciar a atuação profissional lícita e segura. Discussão: A pesquisa foi realizada baseada no código de ética odontológica que se dispõe sobre os direitos e deveres da profissão destacando condutas que devem ser observadas no exercício profissional, definindo as sanções as quais estão sujeitos os Cirurgiões-dentistas em caso de infração, seja de forma indireta ou omissa, sendo esta a necessidade e preenchimento e armazenamento adequado do prontuário odontológico. Estes documentos odontológicos que compõe o prontuário clínico são: Ficha clínica, receitas, atestados, contrato de locação de serviços odontológicos e exames complementares. Conclusão: É necessário estabelecer uma relação de confiança durante todo o tratamento, sempre informado e sendo transparente nas ações, manter um exame clínico detalhado, um prontuário atualizado e organizado de forma que seja de aspectos legais, pois, nos casos de descumprimento das normas do código de ética o profissional sofrerá sanções administrativas.

Palavras-chave: Documentação, Registros Odontológicos, Responsabilidade Legal, Ética Odontológica.

\section{ABSTRACT}

Objective: The aim of this study was to provide knowledge, through a literature review, concerning the responsibility of the Dental Surgeon to know the pertinent legislation, that can substantiate a legal and safe professional activity. Discussion: The research was conducted based on Brazilian Professional Ethical Code of Dentistry that contains rights and duties of the profession, highlighting conducts that should be observed in the clinical practice, setting sanctions to Dental Surgeons in case of infringement, indirectly or by omission, this being the need of fill and proper storage of dental records. The dental documents that compose the clinical records are: clinical sheet, dental recipes, dental certificates, dental services lease agreements and complementary exams. Conclusion: It is necessary to establish a relationship of trust throughout the treatment, always informing and being transparent at actions, keeping a detailed clinical examination, an updated and organized dental record according to the legal recommendations, thus, in cases of noncompliance of the ethical code, the Dental Surgeon will suffer administrative sanctions.

Keywords: Documentation, Dental Records, Legal Responsibility, Dental Ethics.

\section{RESUMEN}

Objetivo: Opresente trabajo tuvo como objetivos proporcionar conocimiento, por medio de una revisión de literatura la responsabilidad del Cirujano-dentista conocer la legislación pertinente conducta que puede sustanciar la actuación profesional lícita y segura. Discusión: La investigación fue realizada basada en el código de ética odontológica que se dispone sobre los derechos y deberes de la profesión destacando

${ }^{1}$ Centro Universitário Cesmac, Maceió-Alagoas. E-mail: fernandapeixoto al@hotmail.com 
conductas que deben ser observadas en el ejercicio profesional, definiendo las sanciones a las que están sujetos los Cirujanos-dentistas en caso de infracción, de forma indirecta u omisa, siendo ésta la necesidad y llenado y almacenamiento adecuado del prontuario odontológico. Estos documentos odontológicos que componen el prontuario clínico son: Ficha clínica, recetas, certificados, contrato de alquiler de servicios odontológicos y exámenes complementarios. Conclusión: Es necesario establecer una relación de confianza durante todo el tratamiento, siempre informado y siendo transparente en las acciones, mantener un examen clínico detallado, un prontuario actualizado y organizado de forma que sea de aspectos legales, pues, en los casos de incumplimiento de las normas del. el código de ética el profesional sufrirá sanciones administrativas.

Palabras clave: Documentación, Registros Odontológicos, Responsabilidad Legal, Ética Odontológica.

\section{INTRODUÇÃO}

As Reformas que ocorreram, a partir dos anos 90, no Código de Defesa do Consumidor, resultaram em mudanças no comportamento dos pacientes que passaram a reivindicar seus direitos na justiça pelos possíveis danos causados durante o tratamento odontológico (ALMEIDA SM, et al. 2016).

Houve um crescimento bastante significativo de litígios envolvendo Cirurgião-Dentista e paciente, pois nem sempre o profissional odontológico consegue comprovar que trabalhou corretamente, porque não se preveniu preparando a documentação adequada e exigível (VANRELL JP, 2002).

Para ter prova em juízo, o profissional deve provar que trabalhou dentro dos princípios éticos e legais preconizados pela ciência odontológica. Sendo assim, o Cirurgião-Dentista precisa ter em mãos um instrumento que comprove suas ações (ALMEIDA SM, et al. 2016).

Este instrumento é o prontuário odontológico que pode ter componentes bastante variáveis, podendo ser composto desde a ficha de avaliação clínica, os planos e a evolução do tratamento até exames complementares, registros fotográficos, modelos, cópias de atestados, de prescrições e de laudos, dentre outros. Além das anotações sobre o estado anterior do paciente, a ficha clinica deve refletir nos atos clínicos realizados,materiais utilizados, detalhar as ocorrências, como as faltas do paciente, falta de colaboração, condições de higienização, e outras situações que possam interferir no resultado esperado pelo paciente ou mesmo pelo profissional (DITTERICH RG, et al. 2008).

O Cirurgião-Dentista torna-se responsável por suas ações ou omissões que suceda prejuízo aos seus pacientes, sendo obrigado a reparar o dano causado. Essa responsabilização pode acontecer no âmbito ético, civil e penal (ALMEIDA SM, et al. 2017).

Desta forma, este estudo visa estabelecer a responsabilidade profissional do Cirurgião-Dentista com o prontuário odontológico como um instrumento de prova da conduta profissional, bem como identificar as principais sanções cíveis, penais e administrativas impostas por erros odontológicos.

\section{METODOLOGIA}

Este trabalho de revisão de literatura aborda a responsabilidade do Cirurgião-Dentista com o prontuário clínico e as sanções impostas por erros odontológicos embasados no Conselho Federal de Odontologia $\mathrm{n}^{\circ}$ 118/12, Código de Ética Odontológica com os artigos n 5, 29 e 30, Código Penal com o artigo n 302, Conselho Regional de Odontologia com 0 artigo $n^{\circ} 7$, Código Civil artigo $n^{\circ}$ 282, Código de Defesa do Consumidor e Constituição Federal, Lei complementar 6.215/75.

Os critérios de inclusão das referências bibliográficas utilizados foram trabalhos publicados no idioma português das bases de dados Scientific Electronic Library Online (SCIELO) e Google Acadêmico nos últimos 10 anos. Foram utilizados os seguintes termos na busca: Documentação. Registros Odontológicos. Responsabilidade Legal. Ética Odontológica. 


\section{DISCUSSÃO}

Os documentos odontológicos que compõe o prontuário clínico podem ser fundamentais (sendo preenchidos em todos os atendimentos realizados ao paciente) ou suplementares (como por exemplo: os exames complementares) segundo (AMORIM HPL, et al. 2016). Assim, os seus componentes são: Ficha clínica, receitas, atestados, contrato de locação de serviços odontológicos e exames complementares (FONSECA JL, et al. 2015).

A ficha clínica é o documento mais complexo do prontuário, sendo produzido durante as consultas, sendo composto por 6 partes: Identificação do profissional, identificação do paciente, anamnese, exame clínico, plano de tratamento e evolução e intercorrências do tratamento (AMORIM HPL, et al. 2016).

$\mathrm{Na}$ etapa da ficha clínica, (Silva RF, et al. 2016) destaca a importância da assinatura do paciente na documentação do prontuário, estabelecendo-se a construção de relação e interação profissional-paciente.

A anamnese consiste em um conjunto de informações acerca dos motivos pela procura do profissional, principais queixas e histórico odontológico, bem como tratamentos realizados anteriormente, sendo colocado o maior número possível de informações. Sendo necessário o registro de problemas observados antes do início do tratamento, podendo-se destacar: Estalidos, redução da abertura de boca, dor na ATM, ocorrência de aftas, herpes labial, sensibilidade dentária e informações sobre os hábitos de higiene oral e dieta. Tais informações podem servir como prova, sendo importante colocar a data e assinatura do paciente ou responsável legal (AMORIM HPL, et al. 2016).

O exame clínico subdivide-se em intraoral e extraoral, realizando-se um reconhecimento das alterações visuais encontradas no campo bucomaxilo-facial, visando obter informações sobre as condições de saúde do paciente. As alterações encontradas devem ser registradas em um odontograma. Alguns autores defendem ainda que a descrição dente por dente é a mais adequada dentro das normas clínicas, administrativas e legais (AMORIM HPL, et al. 2016).

O paciente precisa ser informado sobre todas as possibilidades de tratamento existentes, inclusive aquelas que o cirurgião-dentista que atende o paciente não realiza, sendo esclarecido sobre os procedimentos, técnicas e materiais utilizados e estar de acordo com o plano de tratamento escolhido. Assim, se faz necessário a utilização da assinatura do termo consentimento livre e esclarecido (AMORIM HPL, et al. 2016).

Nesta etapa, deverão ser registradas todos os passos do procedimento executado e intercorrências no método, bem como a mudança de plano terapêutico e faltas a consultas. As receitas são prescritas de acordo com o prontuário odontológico e uma cópia deve ser anexada ao prontuário. De acordo com a Lei 5.081/66, o Cirurgião-dentista está apto a fazer prescrições de produtos farmacêuticos usados em odontologia (BRASIL, 1966).

O Código de Ética Odontológica (CEO) define que as informações obrigatórias da receita são, à partir dos artigos 29 e 30: Nome completo do cirurgião-dentista; Profissão; Número de inscrição no CRO sob cuja jurisdição esteja exercendo sua atividade; Já as facultativas são: As especialidades odontológicas nas quais o Cirurgião-dentista esteja inscrito; Títulos de formação acadêmica mais significativo na profissão;Endereço, telefone, horário de trabalho, convênios e credenciamentos.

Costa, et al. (2008) realizou uma análise de prontuários armazenados em uma clínica odontológica e detectou que aproximadamente $70 \%$ dos prontuários apresenta cópias dos documentos e, destes, o maior número pertence a prescrições de medicamentos $(40,9 \%)$, resultado este que embora elevado, preocupante pela grande quantidade de omissões de documentos.

O atestado emitido pelo cirurgião-dentista é regulamentado pela Lei complementar 6.215/75, permitindo ao profissional atestar, dentro de suas atividades, estados mórbidos e outros para, inclusive, justificar falta no emprego.

Este confere uma autenticidade importante e que enquadra o cirurgião-dentista no artigo 302 do código penal brasileiro - Falsidade de atestado médico, estando sujeito ainda a processo ético, junto ao Conselho 
Regional de Odontologia (CRO) que diz, segundo o artigo 7: "Fornecer atestado que não corresponda à veracidade dos fatos ou dos quais não tenha participado".

O contrato de prestação de serviços odontológicos não é obrigatório, mas configura uma forma de garantir proteção tanto ao paciente quanto ao profissional, tendo validade de até quatro anos. Dentre os exames complementares, destaca-se a radiografia, exames laboratoriais, modelos de gesso e fotografias. Todos os resultados obtidos devem ser devidamente registrados no prontuário e arquivadas para que tenha os efeitos legais desejados (AMORIM HPL, et al. 2016).

Os objetivos para a correta elaboração, arquivamento e guarda dos prontuários odontológicos são amplos e podem variar desde o âmbito clínico ao jurídico, pois seu conjunto de documentos poderá contribuir na tomada de decisões, acompanhamento do caso clínico e verificação da eficácia do tratamento, na identificação de vítimas de violência (in vivo ou post mortem) e/ou óbito, ou como principal instrumento para produzir as provas necessárias à defesa do profissional diante de litígios judiciais que o envolvam (COSTA SM, et al. 2008).

A fim de garantir cada um dos diversos objetivos elencados, diversas regras deontológicas e jurídicas norteiam a elaboração, o preenchimento, o arquivamento e a guarda dos prontuários odontológicos em qualquer modalidade de prestação de serviço - individual/coletivo, público/privado - ou em qualquer formato - físico/digital (COSTA SM, et al. 2008), apesar de se reconhecer que a maneira como cada um elabora seu prontuário odontológico seja livre (FONSÊCA GS, et al. 2014).

Tais regras devem ser aprendidas e executadas ao longo da formação acadêmica em Odontologia, visando o máximo aproveitamento de todos os benefícios, seja ao paciente, ao profissional ou à Instituição de prestação de serviços, que este conjunto de documentos pode fornecer, sensibilizando o graduando sobre a importância do prontuário de saúde e preparando-o para se tornar um profissional organizado e ciente de suas obrigações éticas e legais (OLIVEIRA OF, et al. 2010).

O tempo de guarda do prontuário odontológico é complexo na literatura, sendo uma medida preventiva guarda-lo durante toda vida profissional (OLIVEIRA OF, et al. 2010). De acordo com o Conselho Federal de Odontologia (CFO), através do parecer $n^{\circ}$ 118/12, são obrigatórias a elaboração e a manutenção de forma legível e atualizada de prontuário e sua conservação em arquivo próprio seja de forma física ou digital. A inadimplência do regulamento contidos no CEO é qualificado como infração ética (ALMEIDA SM, et al. 2017).

A utilização do prontuário eletrônico é uma ótima ferramenta, possibilitando a redução de espaço para armazenamento, segurança dos dados obtidos, confidencialidade dos dados do paciente (ALMEIDA SM, et al. 2017). A principal problemática na adoção desta tecnologia é a passividade deste documento a manipulação (FONSÊCA GS, et al. 2014).

O prontuário pertence ao paciente, embora o mesmo não tenha permissão para retirá-lo do consultório, mas de consultar o prontuário, pois cabem ao profissional que o elaborou os seus direitos autorais (AMORIM HPL, et al. 2016).

É importante que o prontuário seja elaborado de forma cautelosa, relatando a condição oral observada (AMORIM HPL, et al. 2016). Detalhar os acontecimentos que vão acontecendo durante todo o tratamento, como as faltas do paciente, falta de colaboração, condições de higienização, e outras situações que possam interferir no resultado. (DITTERICH RG, et al. 2008).

Atualmente o mercado de trabalho está cada vez mais exigente, mais competitivo, fazendo com que os Cirurgiões-Dentistas, adotem condutas de risco como horas cansativas de trabalho, condições operatórias inadequadas, pressa em executar os procedimentos. Estes fatores aliados a uma população informada dos seus direitos tem contribuído para o aumento de litígios contra os profissionais odontológicos (LOLLI LF, et al. 2013).

A responsabilidade dos Cirurgiões-Dentistas envolve as esferas éticas, cíveis e penais. No que se refere as responsabilidades éticas do Cirurgião-Dentista, estas responsabilidades são regidas pelo CEO (Conselho 
de Ética Odontológica), órgão este que regula as normas a serem seguidas pelos profissionais a elas vinculados. Partindo deste pressuposto o Cirurgião-Dentista possui direitos e deveres, regulados pelo Código de Ética que estabelece um conjunto de regras, princípios morais e valores que devem ser respeitados pelo profissional Odontológico. (ALMEIDA SM, et al. 2017).

De acordo com o Código, o Cirurgião-Dentista tem o dever de exercer a profissão mantendo um comportamento digno, elaborar e manter atualizados os prontuários, conforme exposto anteriormente, incluindo e determinando a elaboração e manutenção do prontuário, devendo ser legível e sua conservação em arquivo próprio, seja de forma física ou digital (ALMEIDA SM, et al. 2017).

Nos casos de descumprimento das normas do código de ética, o Cirurgião-Dentista sofrerá sanções administrativas, que vai de uma simples censura, até uma possível exclusão. O órgão competente para impor tais sanções é o CRO (Conselho Regional de Odontologia). Cabe ressaltar que as sanções impostas por este órgão independem das sanções cíveis e penais, (ALMEIDA SM, et al. 2017).

No tocante a responsabilidade Civil, o Cirurgião-Dentista poderá ser responsabilizado por eventuais danos ao paciente, quer seja por negligência ou até por imperícia, devendo haver a figura do nexo de causalidade, ou seja, o liame entre a conduta do agente e o dano causado. As sanções cíveis serão imputadas ao Profissional, quando este infringir alguma norma contida na Constituição Federal, no Código Civil e mormente no Código de Defesa do Consumidor, (ALMEIDA SM, et al. 2017).

De forma bem lacônica, a responsabilidade Civil nada mais é do que o dever jurídico de reparação a um dano sofrido (ALMEIDA SM, et al. 2017). Já a figura da responsabilidade Penal (criminal), que não se confunde com a responsabilidade Civil, ocorre quando o cirurgião-Dentista infringir alguma das normas previstas no Código Penal. Os crimes mais comuns cometidos pelo cirurgião-Dentista, é o de lesão corporal, podendo ser esta de natureza leve ou grave, quase sempre na forma culposa (quando não tem a intenção de pratica-la). Também é comum no meio dos profissionais da odontologia o crime de exercício ilegal da profissão ou exercício ilícito da odontologia, previsto no artigo 282 do CP (Código Penal) art. 282 "Exercer ainda que a título gratuito a profissão de médico, Dentista ou farmacêutico, sem autorização legal ou excedendo-Ihe os limites", (LOLLI LF, et al. 2013).

O prontuário é o principal instrumento de defesa que o Cirurgião-Dentista tem em suas mãos para produzir as provas necessárias diante de litígios judiciais que o envolvam (COSTA SM, et al. 2008). Por isso, faz-se necessário adotar uma nova maneira de trabalho a "Odontologia Defensável" que resguarda os profissionais em eventuais processos (ALMEIDA SM, et al. 2017).

\section{CONSIDERAÇÕES FINAIS}

Diversas situações enquadram o profissional de odontologia no quadro criminal diante de um erro odontológico, casos bastante frequentes neste meio profissional e neste estudo de caso mostrou os princípios morais e valores que devem ser respeitado. ortanto é importante estudar a legislação e aprender a fazer um prontuário apropriado e sempre pensando no bem-estar do paciente, evitando documentação errada para que o trabalho realizado não resulte em um ato criminal.

\section{REFERENCIAS}

1. ALMEIDA SM, CARVALHO SPM, RADICCHI R. et al Aspectos legais da documentação odontológica: uma revisão sobre validade legal, privacidade e aceitação no meio jurídico. Rev Bras Odontol Leg RBOL. 2017; 4(2): 55-64.

2. AMORIM HPL, MARMOL SLP, CERQUEIRA SNN et al. A importância do preenchimento adequado dos prontuários para evitar processos em Odontologia. Arq Odontol, Belo Horizonte. 2016; 52(1): 32-37.

3. BRASIL. Presidência da República. Lei n 5.081, de 24 de agosto de 1966. Regula o exercício da Odontologia. Brasília: Congresso Nacional, 1966.

4. BRASIL. 2004. In: Prontuário odontológico: uma orientação para o cumprimento da exigência contida no inciso VIII do art. $5^{\circ}$ do Código de Ética Odontológica. CFO. Rio de Janeiro: Conselho Federal de Odontologia. Disponível em: <http://www. cfo.org.br> Acesso em 14 de abril de 2018. 
5. BRASIL. 1990. In: Dispõe sobre a proteção do consumidor e dá outras providências. Disponível em: http://www.planalto.gov.br/ccivil_03/Leis/L8078compilado.htm. Acesso em: 14 de abril de 2018.

6. BRASIL. 2012. In: Revoga o código de ética odontológica aprovado pela Resolução CFO 042/2003 e aprova outro em substituição. Rio de Janeiro: Conselho Federal de Odontologia. Disponível em: http://www.normaslegais.com.br/legislacao/resolucao-cfo-118-2012.htm. Acesso em: 14 de abril de 2018.

7. COSTA SM, BRAGA SL, ABREU MHNG et al. Avaliação da Comprovação de Documentos Emitidos Durante o Atendimento Odontológico e do Arquivamento das Radiografias nos Prontuários de Saúde da Unimontes, Montes Claros, Brasil. Pesq Bras Odontoped Clin Integr, João Pessoa. 2008; 8(2): 209-213.

8. DITTERICH RG, PORTERO PP, GRAU P et al. A importância do prontuário odontológico na clínica de graduação em Odontologia e a responsabilidade ética pela sua guarda. Rev Inst Ciênc Saúde. 2008; 26(1): 120-4.

9. FONSÊCA GS, AZEVEDO ACS, DINIZ DSOL et al. Aspectos legais da utilização do prontuário digital na odontologia. RBOL. 2014; 1(1): 69-77.

10. FONSECA JL, BISCONSIN LF, BIANCO LC et al. Aspectos legais do prontuário odontológico. Trabalho de conclusão de curso (graduação) - Faculdade São Lucas, Porto Velho, 2015.

11. LOLLI LF, LOLLI MCGS, MARSON FC et al. Responsabilidade criminal do cirurgião dentista. Acta JUS - Periódico de Direito. 2013; 1(1): 17-23.

12. SILVA RF, PRADO MM, RODRIGUESLG et al. Importância ético-legal e significado das assinaturas do paciente no prontuário odontológico. RBOL. 2016; 3(1): 70-83.

13. VANRELL JP. Odontologia legal \& antropologia forense. 4edc. Rio de Janeiro, editora Guanabara Koogan S.A. 2002. 